\title{
Contingency Model of Multiple SNSs Running Strategy in Art and Cultural Institutions
}

\author{
Joosun Yum ${ }^{1}$, Kihwan $\mathrm{Kim}^{2}$ \& Stephanie Mazzei ${ }^{2}$ \\ ${ }^{1}$ Department of Arts and Cultural Management, Graduate School of Arts and Sciences, Hongik University, Seoul, \\ Republic of Korea \\ ${ }^{2}$ School of Management \& Marketing, College of Business and Public Management, Kean University, New \\ Jersey, USA \\ Correspondence: Kihwan Kim, School of Management \& Marketing, College of Business and Public \\ Management, Kean University, New Jersey, USA. Email: kikim@kean.edu
}

Received: March 31, 2018

doi:10.5539/ijbm.v13n9p13
Accepted: July 6, 2018

Online Published: August 2, 2018

\begin{abstract}
Social Network Service (SNS) is getting popular among various organizations as a powerful tool for communication and promotion. Recently, cultural and art institutions began to employ multiple SNS platforms for a variety of applications such as marketing, communication, customer services, and even program development. It is a challenging task to run multiple SNSs platforms to execute many different applications. Although this is a more common trend, there have been few studies to explore the factors that might influence the successful running of multiple SNSs, in particular in the art and cultural institutions. As critical factors, our study considered three factors, 1) the applications of SNS use, 2) the features of SNS platform, and 3) the characteristics of SNS. From the perspective of contingency theory, we suggested the integrative model that when the fit among these three factors will result in the best outcomes. Using a case study method, we analyzed the case of Daelim museum in order to test our proposed model. We found that the fitness among the target audience, the selection of platform, and the purposes of usage lead to the increased number of audiences and the satisfaction with the services.
\end{abstract}

Keywords: art and cultural institutions, multiple SNSs, SNS applications, Features of SNSs, contingency theory

\section{Introduction}

According to Ellison \& Boyd (2007), social network sites (SNSs) are defined as 'web-based service' which consists of three essential components. This service allows users to construct a private or public profile within a bound system, to show a list of connections to other users, and view not only their list of connections but those made by others. Initially, SNSs were developed for individual uses such as building a social network and information sharing. However, as SNSs gained popularity among people, many companies and institutions started to use SNSs for the purpose of marketing tools or information sharing. Combined with the advancement and adoption of smartphone, SNSs have evolved into a more powerful marketing tool than any other media.

A common feature among diverse SNS is that users have their own unique 'space' (Chung, Marcketti, \& Fiore, 2014). SNSs such as Facebook, Linkedin, Twitter, Pinterest, and Instagram have now become common place in the international virtual space. Social media constitute Web-based applications which facilitate interaction, networking, and the foundation of relationships with and between users (Hausmann, 2012). In SNSs, users can link their space with other people to set up a network. For instance, Facebook or Twitter can reach an unlimited number of followers (Hausmann, 2012). Facebook provides users with the chance to send messages, create groups, share videos and pictures. Twitter also enables users to follow the trend of issues shared by others, share other messages and disseminate short messages.

As institutions were rapid to understand the significance of assuring a proactive online presence, they join social networking (Pulh \& Mencareli, 2015).Currently, SNSs are extensively employed by many different types of organizations such as businesses, educational institutions, government, etc. In the business area, recently-growing social media enable companies to know how social networking service can help them build their brand, reduce costs, increase income and accelerate innovation. These tools also assist them to attract 
partners, employees, and customers (Miranda, Chamorro, Rubio, \& Morgado, 2013). Communication revolution started by SNS brought a new sensation to enterprises' public relations. Hence, leading companies increase promotional works by SNS by making new media advertising team (Han \& Lee, 2013).

Also in the education area, as the technologies designed in SNS have the ability to construct and connect the community in a socially founded network, they help debate and form intimacy between online students (Brady, Holcomb, \& Smith, 2010).Similar to general e-learning advantages, educational benefits of SNS are lower cost, instruction in real time, knowledge crowdsourcing, interconnection and role playing in virtual reality (Weber, 2012). In the interest of renovating government services through online engagement between government and citizens, a lot of governments are arranging budgets to utilize technology. Especially, social network tools can be answered for boosting discussion and sharing information and best practice between public officials, in both interior and exterior communications (Albadi, 2014). Social network service has a lot of progressive and interactive characteristics that help communication among people, so they are useful for a government organization (Weber, 2012).Similar to other types of organizations, art and cultural institutions started to use SNSs as a major marketing and promotion tools to securing the public to audiences. In addition to the use of marketing and promotion, art and cultural institutions have made efforts to use SNSs in innovative ways such as customer service, Q\&A, user participation in contents development, and sharing the contents and performance.

\section{Literature Review}

Although SNSs provide more powerful tools to connect the audiences to the art and cultural organizations, they also leave challenges to marketers and administrators in the organization. The popularity and success of initial SNSs lead to the emerging of a variety of other SNSs. Currently, there exist more than 200 social network sites and new SNSs keep being emerged. Among them, at least 20 SNSs have more than 100 million users. $80 \%$ of the internet users have 5.5 SNS accounts and used 2.8 accounts actively on average (Mander, 2015). This trend of SNS users resulted that most art and cultural institutions are running 3-6 SNSs besides their websites to reach a variety of SNS users. Running multiple SNSs help art and cultural organization to accommodate more variety of existing and potential audiences but it also cast a complicated challenge to SNS marketers and administrators in art and cultural institutions.

First, each SNS platform has different features from one to another. For example, YouTube has its strengths in posting a video clip, allowing the users to post several hours' video clip while Tweeter can provide only 140 charters texts but it spreads over followers quickly and easily. Art and cultural institutions cover a variety of performance natures such as art exhibition, ballet, orchestra, theater, etc. The function of image posting is more crucial of art exhibition while video posting would be more critical for ballet, orchestra, and theater.

Second, each SNS has a little bit different groups of target users based on age, gender, education, location etc. Although young populations dominate the use of SNSs and Facebook has the biggest users, each SNS attracts its unique group of SNS users. For example, Pinterest has four times more female users than male users while $65 \%$ of Facebook users are age 35 or older and its average age of users is getting older (Georgetown University, 2014). So art and cultural institutions should carefully select SNS platforms to match its target audiences.

Third, each art and cultural institutions consider different applications of SNSs. Traditionally SNSs are used as marketing or promotion tools to reach existing and potential audiences. These days, art and cultural institutions started to use SNSs in many innovative ways such as customer service, real time communication, fund raising, audience participation, information sharing, etc. The implementation of these applications is closely related to the features of each SNSs. For example, due to the strong function of texting, Tweeter is used to deliver an important message in the case of emergency or get feedback or opinion for the performance.

Although there have been plentiful studies on the SNS adoption in the art and cultural institutions, no study systematically explore the factors that influence the successful performance of running multiple SNS for the art and cultural institutions. The current study explored three critical factors which are highly likely to be related to the running multiple SNSs: 1) the applications of SNS, 2) the features of SNS platform, and 3) the characteristics of SNS users. In addition to the discussion of the factors, we suggest the interactive model of these factors from the contingency theory. The tenet of contingency theory discusses that the design of an organization and its subsystems should have a fit with its external environment and when there is a misfit among them, successful performance is not guaranteed. For example, when there is fit among the structure of, the technology used by, and the environment of the organization, the organization can have the best performance. Essentially, contingency theory argues that there is no one optimal method for designing and managing organizations (Kast \& Rosenzweig, 1973; Wadango\& Abdel-Kader, 2014). The contingency model discusses that each factor influences the performance of SNSs, interacting with other factors but the overall performance will be 
determined by each factor and the fit among the factors as well.

\section{Research Methodology}

In the consideration of the nature of our proposed model, we employed a case study method to test the model. Case studies emphasize detailed contextual analysis of a limited number of events or conditions and their relationships. In particular, in the social science discipline the case study method has been used to examine contemporary real-life situations and provided the basis for the application of ideas and extension of methods. The case study research method is an empirical inquiry that investigates a contemporary phenomenon within its real-life context (Yin, 1984, p. 23).

After searching more than 10 candidate cases we selected the case of Daelim museum. While most art institutions use SNSs for just sharing the schedules of exhibition or program introduction, Daelim Museum has used SNSs in a variety of ways, trying to communicate with visitors as well as captivate users by various contents and events. Daelim museum carefully selects the platform of SNS considering the purpose of information sharing and the nature of information contents, which can be text, image, video clip or all combinations. In particular, as an art museum, it tried to maximize visual impact on SNSs users.

First of all, Daelim makes the best use of image and text to touch users' sensitivity. Often, the contents which arouse intense feelings such as grief, happiness and move are eminently contagious. Likewise, Daelim art museum's SNSs are full of images which are taken by professional photographers. The combination of sensible photos and emotional texts provided a powerful tool for active advertising and marketing. Daelim employed Facebook and Instagram because they provided the best platform for posting pictures and texts. Instead of detailed work explanations, the biggest advantage of posting images with a concise phrase, as a tool of marketing, is to touch people's emotional side deeply. Therefore, Daelim art museum not only can arouse people's sympathy but also forge intimate image beyond the traditional art museums' image. However, the museum uses Twitter to deliver real time multimedia contents which happen in the art museum, rather than attaching weight to emotion contents.

Secondly, beyond delivering information, Daelim makes the best use of SNSs in order to convert SNSs users to visitors through its diverse events. For example, when the museum hosted the Karl Lagerfeld's photo exhibition, it arranged a surprise event to offer a free admission to SNSs followers. This event encouraged SNSs users to actively share the valuable information of free admission and the exhibition with other users, making the users a volunteer marketer for the exhibition. Using SNSs, Daelim created another interesting event, "opening the museum for a closed day" only for social media neighbors. If the event information shared by SNSs users exceeds a certain number, the art museum would be opened for free on a closed day just for social media neighbors. This event made SNSs users excited in that they could open the museum on the even closed day for only themselves. Unlike other art museums of which target audiences are people older than the 20s, Daelim's audience distribution chart $(20 \mathrm{~s}: 75.4 \%, 30 \mathrm{~s}: 18 \%, 40 \mathrm{~s}: 3 \%)$ shows this museum is a playground for young people thoroughly. The exhibitions are also more outside mainstream or diverse culture which suits the 20s' fancy than traditional exhibitions, so they are always popular (Park, 2016). Characteristically, Daelim's targets are the 20s and 30s called SNS generation. This kind of sensible contents move young generation's heart, so they still draw steadily their interest and response. As the case illustrated, Daelim art museum's successful use of SNSs lie in several factors; a variety uses of SNS, the selection of platform, and understanding of the demographics of target users.

\section{Discussion}

\subsection{Applications of SNSs in Art and Cultural Institutions}

Initially, SNS was devised to meet users' personal purposes such as building networks and sharing information with friends or other people. However, these days many art and cultural institutions have developed a variety of applications of SNSs in innovative ways. For example, museums use SNS for micro-fundraising; enlisting small donations online from a large number of people and crowdsourcing which is a utilizing idea by soliciting online contributions from a number of people. It is also used for engagement with audiences and increased communication, which represents SNS could have a positive effect on cultivating museum-visitor relationships (Chung et al., 2014).

Art and cultural institutions have developed several major applications. First, SNS is utilized for information offering, which is the typical use of SNS. Most cultural and art institutions share the information of education program, events, performance, and exhibition through Facebook or Twitter (Jung, Cho, \& Kim, 2010).Tate museum uploads birthday wishes for popular artists and makes people see their artworks online. It also makes 
videos of the preparation process of exhibitions for people to see how the artists arrange their artworks (Kim, 2012). Similar to the case of Tate museum, Sabina art museum enables people to enjoy the information of exhibition, photos and artist's interview by QR cord service (Kim, Seo, Kang, Kwon, \& Lee, 2013). The National Media Museum shares rich media of their large collection as growing their range to involve people with even an ephemeral interest in film and photography (Milbrath, 2013).

Second, as SNSs are gradually emphasized for marketing and promotion tools, more culture and art institutions adopt SNSs by means of marketing and active public relations beyond just simple information delivery (Spiliopoulou et al., 2014). For example, National Australian Ballet uploaded a daily scene and practice of shows or Broadway musical, 'Next to Normal' offered its script through Twitter. These cases show maximized aspect of publicity effect through quality service (Kim et al., 2011). Artists in cultural art institutions use SNS to makes the public get interested in arts. In the case of Daelim art museum in Korea, it stimulates visitors' curiosity by abundantly describing art works with emotional phrases and sensuous images instead of explaining the works (Park, 2012). In the case of the national dance company of Korea, as showing a part of various contents, it aroused people curiosity and linked related photos (Lim, 2011).

Third, SNS enables users' active participation. It attracts voluntary participation from users and expands the base of a creator by extending the main agent of a creator to the public. The case of Brooklyn museum, New York, shows the big transition of the exhibition processes by engaging users in series of processes such as exhibition plan, work selection, and marketing completely (Moon, 2013). The Victoria and Albert Museum has executed the series of projects promoting families for making their own digital images (Camarero, Jose, \& San, 2016).The project 'Dear Photograph' and the collaboration at 'The One Million Masterpiece' are a good example to show that a single huge art work is created by a number of ordinary people's collaboration. Therefore, it contributes group cultivation of creative prosumers. The case of Guggenheim museum's Youtube play and Royal opera house's collaborative script creation leads phenomenon breaking up the boundary of cultural art and cultural enterprise in that users participate in creating (Kim et al., 2011; Moon, 2013).

Fourth, SNS enables the audiences to utilize the contents of the art and cultural institutions. Brooklyn museum designed ArtShare application for Facebook users in order that people upload art works in museum freely and share them with friends. It is ArtShare's purpose that users use museum contents, so people exhibit their photos, paintings, and objects in their own spaces. Powerhouse Museum's museum collection database also provides a function capable of attaching individual information or knowledge in each collection (Koo, 2011). Art Gallery NSW has 'Art Sets' for audiences to make their own gallery or share with the public as people can store videos and art works with their text or photos (Meng, 2015).In Amsterdam, the Rijksmuseum lets people can edit and reproduce with art works by making its collection available as open space (Gilbert, 2016).Therefore, SNS helps cultural art institutions to interact with an extensive audience who may not be interested or curious about art institutions.

Fifth, SNS is used for customer service. SNS makes it possible not only to receive all sorts of inquiry but to provide answers immediately. People can get help to solve problems from SNS without visiting service centers (Spiliopoulou et al., 2014).Lincoln center provides a good example of this. It announced emergency by using SNS when the upcoming violinist's performance was canceled because airline service is suspended due to the eruption of the volcano (Jung et al, 2010). Brooklyn Museum has an application by which visitors can ask questions about artwork to curators in real time (Gilbert, 2016).Using Tweets, Tate museum contacts consumers personally, sending messages up to six times a day. The messages include various contents such as unknown stories behind the exhibition or a weekly schedule. Especially, it carries on conversation throwing diverse questions to followers through Twitter (Kim, 2012). Korean Folk Village's Twitter accounts, 'Folk Village Lady', built trust and intimacy by replying answer one by one to followers' mention at the early stage (Kim et al., 2011).

\subsection{The Features of SNS Platforms}

Each SNS platform provides its users with a variety of experience by offering unique features. Although each SNS provides its own features, common features of SNSs include 1) video, 2) image, 3) text, 4) real time communication, and 5) interlocking to different SNS platforms.

Video posting. Video posting function enables the users to post and share the video clips which were captured using their camera or existing ones. In particular, YouTube even allows users to post several hours-long video clip. One of the great advantages of video sharing function is that it can provide both video and audio features. In particular, for performing arts institutions such as orchestra, ballet, musical, and play they can share some part of their performances with users, providing the information of the performance and attracting audiences' interest as well. For example, National Australian Ballet or Broadway musical, 'Next to Normal' uploaded a daily scene. 
Recently some SNS provides real-time broadcasting function.

Image. Another important feature of SNS is that it allows users to share pictures with others. Some SNSs can share real time captured pictures with other users. For example, Instagram, which is focused on Image sharing, can apply diverse effects to pictures such as filtering and reshaping, creating better impressions for the pictures. In particular, it features a picture size of rectangle share that gives an impression of Polaroid. One of the great advantages of image sharing is that it can leave a deep impression to people without any wordy explanation. Especially, this function can be used by art galleries or museums to make people who experience colorful and emotional pictures filtered by Instagram feel an impulse to visit. For example, Brooklyn museum designed ArtShare application for Facebook users in order that people upload art works in museum freely and share them with friends. It is ArtShare's purpose that users use museum contents, so people exhibit their photos, paintings, and objects in their own spaces (Gilbert, 2016).

Text. Posting text type of information is a common and basic function of most SNSs. Most of SNSs can share and interact personal opinions or information through text function. In Twitter, information sharing is mostly main purpose among the users by using very short sentences such as a text message. Short sentences composed of 140 words and less convey the messages to the general public and spread them very quickly and broadly. The biggest benefit of text is its convenience. People can send and receive information freely via any SNSs. It is the most effective way to communicate information. With text function, many cultural and art institutions have the form of relay broadcasting and they concentrate on uploading scenes immediately on the spot. For example, Tate Museum contacts with consumers personally by tweets such a message. As it sends tweets up to six times a day, the contents are various from unknown stories from the exhibition to a weekly schedule. Especially, it carries on conversation throwing diverse questions to followers through Twitter (Kim, 2012).

Table 1. Analysis of SNS Platforms' Strengths and Weaknesses

\begin{tabular}{llllll}
\hline Main Features & Video & Picture & Text & $\begin{array}{l}\text { Real time } \\
\text { connection }\end{array}$ & $\begin{array}{l}\text { Connection } \\
\text { other SNSs }\end{array}$ \\
\hline Facebook & Strong & Strong & Strong & Medium & Medium \\
YouTube & Strong & Weak & Weak & Weak & Weak \\
Tumblr & Strong & Strong & Strong & Strong & Medium \\
Pinterest & Weak & Strong & Weak & Medium & Medium \\
Instagram & Medium & Strong & Weak & Strong & Strong \\
Twitter & Medium & Medium & Strong & Strong & Medium \\
LinkedIn & Weak & Strong & Strong & Medium & Medium \\
\hline
\end{tabular}

Real time communication. This feature enables users to communicate more easily and quickly through SNS platform in real time. Facebook provides text message and audio and video call services, enabling its users to communicate in real time. However, this communication is limited to only one to one. Tweeter is more powerful in this function. It can spread messages to multitude at the same time. Real time communication function is very useful in the case of emergency or when requiring immediate feedback. When audience in the museum asked a question through Tweeter, the museum quickly responded to the audience's question or request. For example, Brooklyn Museum has an application as visitors can ask questions about artwork to curators in real time (Gilbert, 2016).

Connection to other SNS. However, using so many kinds of SNSs caused the problem that users are confused what they uploaded to which SNSs. Also, it is inconvenient to post texts, pictures, or videos to many different SNSs. For this reason, some SNSs provide a unique function that the contents of the SNSs can be shared with other SNSs. there is a new way to use simultaneously many SNSs through just one SNS. Representatively, Instagram is possible to interlock directly with several SNS accounts. Unlike the other SNSs, Instagram is possible to send postings to Facebook, Twitter, Tumblr, and Flicker etc. However, this function is not available in vice versa. Naver, SNS in South Korea provides the services by which its users can post their pictures to both Naver and Facebook at the same time. This function benefits users in many ways. First, it helps to save time and energy in managing SNSs. As discussed above, people tend to adopt many SNSs. So it can be time and energy consuming in managing many different SNSs. In addition, it helps to spread information to a broader scope of people by enabling to connect to other SNSs.

Table 1 analyzed the strengths and weaknesses of each SNS platform in terms of the functions that we discussed 
above. Each SNS has its own strengths in certain features, not all the features. For example, YouTube has more strengths in posting video clips while Instagram is more specialized in posting pictures. These strengths and weaknesses might cause the users to develop their preferences to certain SNS platform.

\subsection{The Demographic Characteristics of Users}

Understanding the characteristics of SNS users will play a critical role in developing the successful SNS running strategy. Although major SNS users are young population, demographics of SNS users are getting diverse. As a result of that, a certain age or gender group prefer a certain type of SNS platform. For example, Twitter is popular among people of 18-29 ages and to urban or suburban people than rural people. Unlike Twitter, the average age of Facebook users is getting older. $65 \%$ of Facebook users are age 35 or older and highest usage age group is between 45-54 years old (Georgetown University, n.d.). In the case of Tumblr, $67 \%$ of users are under age 35 and skews slightly female (54\% vs. $46 \%$ ); nearly half of users have a college education particularly popular among Hispanic. Most of Pinterest users are women (81\%) and the prevalent age range is under 40 (Aslam, 2017). Unlikely other SNS platforms are typically used by women than men, LinkedIn has significantly more male (63\%) users than female users (37\%) (Hampton, Goulet, Rainie, \& Purcell, 2011). Table 2 summarized the demographic information of users of each SNS.

Table 2. User Demographic Information of various SNSs

\begin{tabular}{|c|c|c|c|c|c|}
\hline & Gender & Age & Education & Income & Location \\
\hline \multirow[t]{4}{*}{ Facebook } & Male: $75 \%$ & $18-29: 88 \%$ & HS: $77 \%$ & $\$ 30 \mathrm{~K}$ less: $84 \%$ & Urban: $81 \%$ \\
\hline & & $30-49: 84 \%$ & College: $82 \%$ & $\$ 30-50 \mathrm{~K}: 80 \%$ & Suburban:77\% \\
\hline & Female: $83 \%$ & 50-64: $72 \%$ & College $+: 79 \%$ & $\$ 50-75 \mathrm{~K}: 75 \%$ & Rural: $81 \%$ \\
\hline & & $65+: 62 \%$ & & \$75k more:77\% & \\
\hline \multirow[t]{4}{*}{ Twitter } & Male:24\% & $18-29: 36 \%$ & HS: $20 \%$ & $\$ 30 \mathrm{~K}$ less: $23 \%$ & Urban: $26 \%$ \\
\hline & & $30-49: 23 \%$ & College: $25 \%$ & $\$ 30-50 \mathrm{~K}: 18 \%$ & Suburban:24\% \\
\hline & Female:25\% & $50-64: 21 \%$ & College $+: 29 \%$ & $\$ 50-75 \mathrm{~K}: 28 \%$ & Rural: $24 \%$ \\
\hline & & $65+: 10 \%$ & & $\$ 75 \mathrm{k}$ more: $30 \%$ & \\
\hline \multirow[t]{4}{*}{ LinkedIn } & Male: $31 \%$ & 18-29: $34 \%$ & HS: $12 \%$ & $\$ 30 \mathrm{~K}$ less: $21 \%$ & Urban: $34 \%$ \\
\hline & & $30-49: 33 \%$ & College: $27 \%$ & $\$ 30-50 \mathrm{~K}: 13 \%$ & Suburban: $30 \%$ \\
\hline & Female:27\% & 50-64: $24 \%$ & College $+: 50 \%$ & $\$ 50-75 \mathrm{~K}: 32 \%$ & Rural: $18 \%$ \\
\hline & & $65+: 20 \%$ & & $\$ 75 \mathrm{k}$ more: $45 \%$ & \\
\hline \multirow[t]{4}{*}{ Pinterest } & Male: $17 \%$ & $18-29: 36 \%$ & HS: $24 \%$ & $\$ 30 \mathrm{~K}$ less: $30 \%$ & Urban: $30 \%$ \\
\hline & & 30-49: $34 \%$ & College: $34 \%$ & $\$ 30-50 \mathrm{~K}: 32 \%$ & Suburban:34\% \\
\hline & Female: $45 \%$ & $50-64: 28 \%$ & College $+: 34 \%$ & $\$ 50-75 \mathrm{~K}: 31 \%$ & Rural: $25 \%$ \\
\hline & & $65+: 16 \%$ & & $\$ 75 \mathrm{k}$ more: $35 \%$ & \\
\hline \multirow[t]{4}{*}{ Tumblr } & Male: $10 \%$ & 18-29: $20 \%$ & HS: $10 \%$ & $\$ 30 \mathrm{~K}$ less: $16 \%$ & Urban: $16 \%$ \\
\hline & & $30-49: 11 \%$ & College: $13 \%$ & $\$ 30-50 \mathrm{~K}: 8 \%$ & Suburban: $8 \%$ \\
\hline & Female: $11 \%$ & $50-64: 5 \%$ & College $+: 9 \%$ & $\$ 50-75 \mathrm{~K}: 4 \%$ & Rural: $3 \%$ \\
\hline & & $65+: 2 \%$ & & $\$ 75 \mathrm{k}$ more: $11 \%$ & \\
\hline \multirow[t]{4}{*}{ Instagram } & Male: $26 \%$ & 18-29: $59 \%$ & HS: $27 \%$ & $\$ 30 \mathrm{~K}$ less: $38 \%$ & Urban: $39 \%$ \\
\hline & & $30-49: 33 \%$ & College: $37 \%$ & $\$ 30-50 \mathrm{~K}: 32 \%$ & Suburban:28\% \\
\hline & Female:38\% & 50-64: $18 \%$ & College $+: 33 \%$ & $\$ 50-75 \mathrm{~K}: 32 \%$ & Rural: $31 \%$ \\
\hline & & $65+: 8 \%$ & & $\$ 75 \mathrm{k}$ more:31\% & \\
\hline
\end{tabular}

As SNSs are getting popular, there are more and more specialized SNSs which focus on specific interest such as Job recruit, hobbies, and profession etc. For example, LinkedIn is business-oriented social networking service mainly used for sharing news/discussions of company and industry. Employers can list jobs and search for potential candidates. Users can post their own photos and view photos of others to aid in identification. Users can follow different companies and can receive notifications about the new joining and offers available. "Deviant Art" is the largest online social network for artists and art enthusiasts. It numbers more than 35 million registered members and attracts over 65 million unique visitors per month. It is also a platform for "emerging and established artists to exhibit, promote, and share their works with an enthusiastic, art-centric community," according to the site (Chaney, 2015). 


\subsection{Development of an Integrative Model from Contingency Perspective}

There have been many studies to examine the factors for the successful SNSs use. However, our study attempt to develop a model to show how each variable interacts with other variables from the contingency perspective. Contingency theory has been broadly adopted by organization theory and behavior areas. According to Kast and Rosenzweig's (1973) definition of contingency theory, the contingency view of organizations and their management suggests that an organization is a system composed of subsystems and delineated by identifiable boundaries from its environmental supra-system. The contingency view seeks to understand the interrelationships within and among subsystems as well as between the organization and its environment and to define patterns of relationships or configurations of variables. It emphasizes the multivariate nature of organizations and attempts to understand how organizations operate under varying conditions and in specific circumstances. Contingency views are ultimately directed toward suggesting organizational designs and managerial practices most appropriate for specific situations. Essentially, contingency theory argues that there is no one optimal method for designing and managing organizations (Kast \& Rosenzweig, 1973; Wadango \& Abdel-Kader, 2014). This differs from "one size fits all" models, which are criticized for being too general and ignoring the uniqueness of programs and organizations (Radin, 2006). It emphasizes the fit relationship among internal and external variables. The tenet of contingency theory discusses that the design of an organization and its subsystems should have a fit with its external environment and when there is a misfit among them, successful performance is not guaranteed.

\subsection{Fit among Applications, Features, and User Characteristics of SNSs}

We contend that this still applies to art and cultural institutions in running multiple SNSs. The factors we discussed play important roles in determining the effectiveness of SNSs not separately but interactively. From the contingency perspective, when running multiple SNSs, the art and cultural institution must seek the fit among characteristics of users as an external variable, applications of SNSs as management systems or internal factors, and features of SNSs as a tool. Misfit or mismatch among these factors will result in less effective performance.

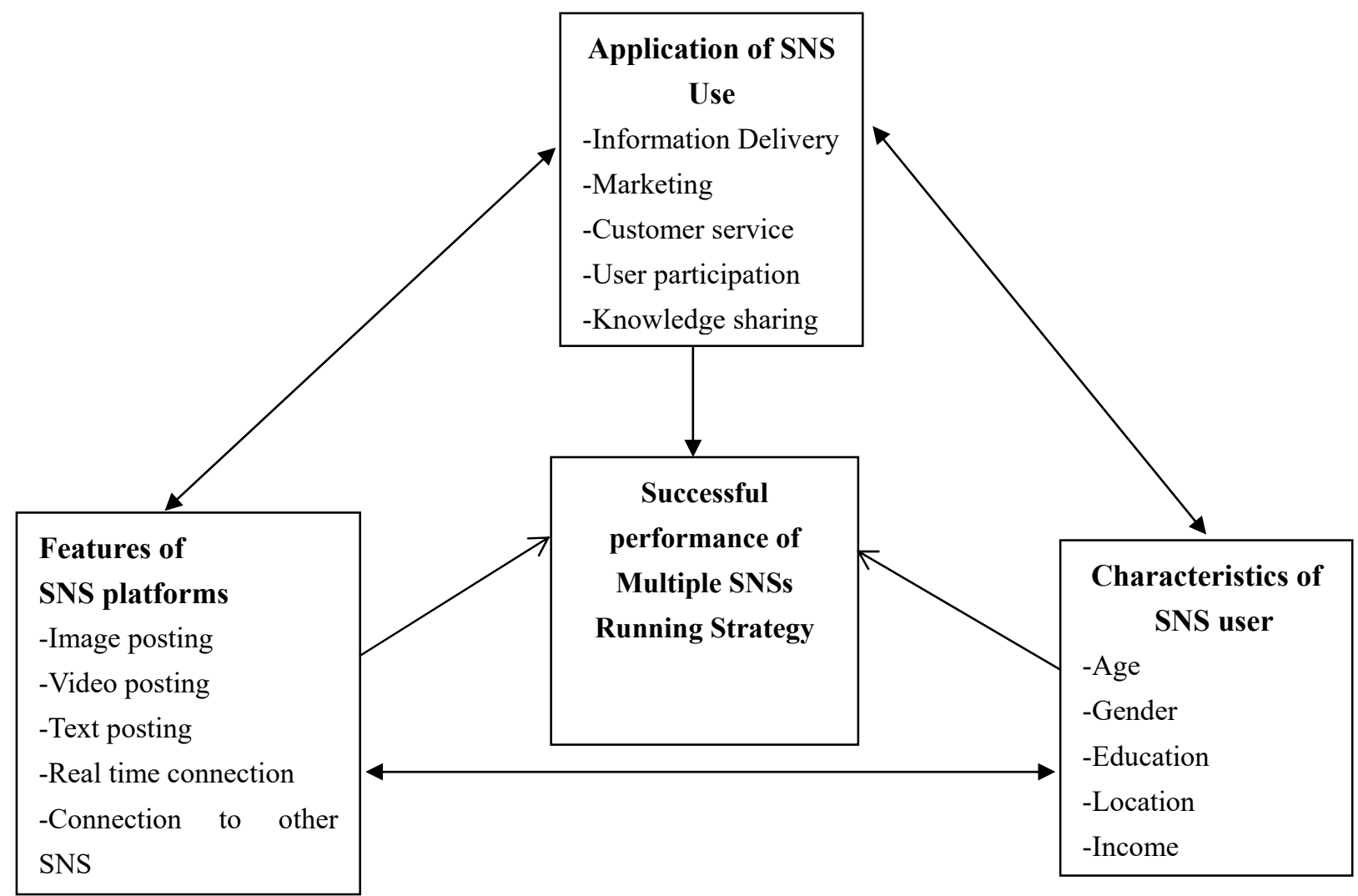

Figure 1. Integrative Model for Multiple SNSs Strategy 


\subsection{Applications and Features of SNSS}

We discussed that art and cultural institutions have used SNSs in innovative ways beyond just delivering

information and marketing. To maximize the effectiveness of the intended purposes, the institutions should take the features of SNS platforms into consideration when choosing appropriate SNSs. For information delivery or marketing, the institutions make the nature of contents fit with the features of the SNSs platform. For example, using You Tube, New York City ballet regularly shared the short practice scene with its audiences, raising the interest from audiences. In the case of customer services, National Science Museum used Twitter for customer services. If the museum's audiences can ask questions or help through Twitter, it responded to the questions or help in real time. It took advantages of Twitter's text function and real time communication features for the customer service purposes. Most small and medium sized museums suffer from the lack of resources to create contents. The museum of East Anglian life in U.K. actively used SNSs to create contents through the participation from audiences. One of the museum's SNSs is Flickr, which focused on a chat room called FlickrLive with real-time photo exchange capabilities. The museum encourages audiences to post the pictures through Flicker and use the posted pictures by the audiences for marketing the event of the museum. Also, it develops a new story from the audiences' chat about the museum's exhibition (Chaney, 2015).

\subsection{Application and Characteristics of SNS Users}

Although most SNSs cover broad ranges of demographic characteristics of users such as gender, age, education, income, location, etc., to some degree, they are skewed to certain population groups. As we discussed earlier, in the case of Tumblr, $67 \%$ of users are under age 35 and nearly half of users have a college education particularly popular among Hispanic. Most of Pinterest users are women (81\%) and the prevalent age range is under 40 (Aslam, 2017). Usually, information delivery and marketing has been the most common applications of SNSs for most art and cultural institutions. For this purpose, the institutions consider employing the SNS that has the most and broadest range of users or the one that has specific target audiences. The institutions need to carefully select the SNSs that best match their target audiences. For example, Daelim museum in South Korea target young audiences, employing Facebook and Instagram. The museum is a playground for young people thoroughly. The exhibitions are also more outside mainstream or diverse culture which suits the 20s' fancy than traditional exhibitions, so they are always popular (Park, 2016).

\subsection{Features and Characteristics of SNSS}

Some features of SNSs are likely to appeal to certain groups of users. Unlike website or blog, which allows mostly one side communication, SNSs allow users to communicate both sides. Most adult populations take a passive stance in using SNSs but young populations keep seeking the way to engage in contributing to the organizations' SNSs. Young populations are more likely to connect to and share their contents with new people. This is why Twitter is more popular for the young generation than the old generation. Also, young population is eager for taking, posting, and watching the video clip. The uploaders of the video clips in YouTube are mostly young people, in turn, which attract young audiences. In the future, new SNSs will be emerged based on developing new features applying new technology and creating a new community. The SNSs with new features will attract younger populations who are open to newness.

\section{Conclusions}

\subsection{Implication/Suggestion for Practitioners}

This research suggests several practical tips on how to use SNS for marketers and administrators in cultural art organizations such as art galleries, museums, and theaters. As previously mentioned in this research, basically art and cultural institutions carefully design the use of SNS according to their situations.

Most art and cultural institutions employ many different SNSs at the same time. Although the institutions can utilize an unlimited number of SNSs, they carefully consider choosing a few SNSs that can target most audiences. Major SNSs such as Facebook, Tweeter, Instagram, or Pinterest embrace broad populations. However, recently many new SNSs that target specialized groups are emerging. If the art and cultural institutions aim to target these specialized group, they might consider the niche SNSs. Second, when art and cultural institutions consider their main SNS platforms, they need to carefully consider the purposes and types of SNSs use such as announcing news, sharing a part of a scene, attracting the feedback from audiences, having events, etc. Recently, some SNSs introduced a new feature such as a 360-degree picture or live cam. Third, organizations have to set clear the guidelines and policies on who will be in charge, how much and often information will be open through SNS, and how to protect customers' privacy before they begin SNS service. Fourth, since SNS is not unilateral but interactive communication method and there are various SNSs with different functions and features, 
organizations should carefully select a staff member who is proficient in a variety of SNSs in order to effectively respond to users' demands or questions (Jung et al., 2010). Fifth, cooperation with the celebrities and the influential people who engage actively in SNS could have a big positive impact on the promotion or the publicity of culture and art institutions. Sixth, people's interest in certain organization's SNS heavily depends on the attractiveness of the institution itself of their own and the contents provided. In order to retain attention from the users, it is critical for art institutions to create diverse and interesting contents or events through SNS.

\subsection{Future Research Issues}

In this study, we introduced the contingency model of running multiple SNSs considering three important factors which are likely to determine the effective performance of SNS. Future research might need to test our model empirically using data collected from art and cultural institutions. Besides, with more research on the other factors, it could be applied to enterprises, government, educational institutions for their multiple SNSs uses. Finally, we considered three factors that might influence the successful use of SNSs. Future research might need to explore more factors to lead to the successful use of SNSs.

Unlike businesses, most art and cultural institutions face limited budgets for developing and promoting the programs. SNSs provided a new opportunity to contact audiences and promote their programs. In the future, more and more art and cultural institutions will adopt SNSs for many purposes but just adopting doesn't guarantee the effective out comes. In order to make positive effectiveness, cultural art institutions are not only supposed to offer or promote information about exhibitions or performances by SNS. They have to establish interactive communication framework so that visitors can have continuing interests and participations than before (Han \& Lee, 2013).

Currently, the roles of SNSs in the art and cultural organizations keep being expanded beyond just marketing and communication. Due to the success and popularity, a new kind of SNS will be emerged, appealing to specific groups of audiences. The advancement in IT will enable SNSs to gear new features which are not available in the past. These new trends will provide opportunity but threat as well. The dynamics caused by the emergence of new SNSs, technologies, and applications challenge marketers and administrators in the art and cultural institutions in running multiple SNSs. Administrators and marketers in art and cultural institutions carefully design and implement multiple SNS running strategy that understand the intended applications, features of SNSs and user characteristics.

\section{References}

Al-Badi, A. H. (2014). The adoption of social media in government agencies: Gulf cooperation council case study. Journal of Technology Research, 5, 1-26.

Aslam, S., (2017). Pinterest by the numbers: Stats, demographics \& fun facts. O mnicore. Retrieved January 31, 2017 from https://www.omnicoreagency.com/pinterest-statistics/

Boyd, D., M., \& Ellison, N. B. (2007). Social network sites: Definition, history, and scholarship. Journal of Computer-Mediated Communication, 1, 210-230. https://doi.org/10.1111/j.1083-6101.2007.00393.x

Brady, K., P., Holcomb, L., B., \& Smith, B. V. (2010). The use of alternative social networking sites in higher educational settings: A case study of the e-learning benefits of Ning in education. Journal of Interactive Online Learning, 9, 151-170.

Brittney, H. (2016). Pinterest for business: Everything you need to know. Business and News Daily. Retrieved May 15, 2016, from http://www.businessnewsdaily.com/7552-pinterest-business-guide.html

Camarero, C., Jose, G. M., \& San, J. R. (2016). Efficiency of web communication strategies: The case of art museums. International Journal of Art Management, 18, 42-92.

Chaney, P. (2015). Niche social networks for small business marketing. Practical Ecommerce. Retrieved June 1, 2017 from http://www.practicalecommerce.com/10-niche-social-networks-for-small-business-marketing

Chung, T., Marcketti, S., \& Fiore, A., M. (2014). Use of social networking services for marketing art museums [Electronic Version]/Museum Management and Curatorship, 29, 188-205. https://doi.org/10.1080/09647775.2014.888822

Corcione, D. (2017). Social media for business: A marketer's guide. Business News Daily. Retrieved January 28, 2017 from http://www.businessnewsdaily.com/7832-social-media-for-business.html

Georgetown University. (2014). Social media platform comparison: Key channel trends \& features to inform your story sharing process. Retrieved June 13, 2016, from 
http://meyerfoundation.org/sites/default/files/files/SWTPlatform-Comparison-090414.pdf

Gilbert, S. (2016). Please turn on your phone in the museum. The Atlantic, Article. Retrieved December 7, 2016 from http://www.theatlantic.com/magazine/archive/2016/10/please-turn-on-your-phone-in-the-museum/497525/

Han, A. R., \& Lee, J. S. (2013). The current status of PR activity and strategy analysis of domestic museums' Facebook. Korean Association of Arts Management, 27, 101-133.

Hannon, K. (2016). Museums, the new social media darlings. The New York Times, Article. Retrieved December 6, 2016 from http://www.nytimes.com/2016/10/30/arts/design/museums-the-new-social-media-darlings.html?_r=1

Hausmann, A. (2012). The importance of word of mouth for museums: An analytical framework [Electronic Version]/International Journal of Art Management, 14, 32-43.

Inc. (2010, January 25). How to use social networking sites to drive business. Retrieved Nov 18, 2016, from http://www.inc.com/guides/using-social-networking-sites.html

Jeong, Y. J., \& Bae, J. A. (2016). The study of cultural art institution's social media use. Korean Association of Arts Management, 39, 5-31.

Jung, H., Cho, H., \& Kim, G. (2010). The guide of SNS promotion: From the cases of foreign art and cultural institutions. Analysis of New Trends, 9, 274-306.

Kast, F., \& Rosenzweig, J. (1973). Contingency views of organization and management. Chicago, IL: Science Research Associates Inc.

Kim, H., Park, J., Park, S., Kang, H., Lee, Y., Jeong, S., \& Oh, Y. (2011). A study on successful application cases of social media in culture area [Electronic Version]/National Information Society Agency, 1, 1-137.

Kim, J. (2012). A study on public relations and exhibitions of art museum through integrated marketing communication (IMC) (Unpublished doctoral dissertation). The Hongik University Graduates School of Art, $1-94$.

Kim, J., Seo, H., Kang, J., Kwon, S., \& Lee, H. (2013). Arts management academy LINK: The cases of promoting and marketing in cultural art field. Seoul, Korea: Korea Arts Management Service Center.

Koo, B. K. (2011). The study of the change impacting on museum environment through information technology development. Korean Association of Arts Management, 20, 5-29.

Lee, D. (2012, July 3). Analysis of Daelim art museum's social media strategy of application. Peak 15 - The Blog. Retrieved July 3, 2016 from http://peak15.tistory.com/344

Lim, H. S. (2011). The study on marketing based on digital media of dance performing arts organization and henceforth task. Korean Association of Arts Management, 18, 95-119.

Mander, J. (2015). Internet users have average of 5.54 social media accounts. GlobalWebIndex - The Blog. Retrieved June 1, 2017 from http://blog.globalwebindex.net/chart-of-the-day/internet-users-have-average-of-5-54-social-media-accounts/

Meng, R. (2015). Social media and cultural institutions. Meco6936 - The Blog. Retrieved January 2, 2016 from https://meco6936.wordpress.com/2015/05/29/social-media-and-cultural-institutions/

Milbrath, S. (2013). The best ways for museums and art organizations to be social. Hootsuite - The Blog. Retrieved December 24, 2016 from https://blog.hootsuite.com/social-museums-art-organizations/

Miranda, F., J., Chamorro, A., Rubio, S., \& Morgado, V. (2013). Journal of internet banking and commerce [Electronic version]/Journal of Internet Banking and Commerce, 18, 1-17.

Moon, J. (2013). Marketing plan using social media for cultural institutions (Unpublished doctoral dissertation). Dankook University, 1-69.

Park, D. (2016). Why millennials are enthusiastic about Daelim museum? Photohisoty - The Blog. Retrieved April 27, 2016, from http://photohistory.tistory.com/16382

Park, S. (2012). A successful example of SNS marketing: Daelim art museum. Ewha Brand Communication The Blog. Retrieved October 12, 2012, from https://ewhabrandcommunication.wordpress.com/2015/10/12/

Pew Research Center. (2011). Social networking sites and our lives. Retrieved April 8, 2016, from http://www.pewinternet.org/2011/06/16/social-networking-sites-and-our-lives/ 
Pew Research Center. (2016). Social Media Update 2016. Retrieved May 21, 2016, from http://www.pewinternet.org/2016/11/11/social-media-update-2016/

Pulh, M., \& Mencareli, R. (2015). Web 2.0: Is the museum-visitor relationship being redefined? [Electronic version]/International Journal of Art Management, 18, 43-51.

Radin, B. (2006). Challenging the performance movement: Accountability, complexity and democratic values. Washington, DC: Georgetown University Press.

Seltzer, D. (n. d.). Comparison chart for choosing between top social media sites for marketing. Small Business

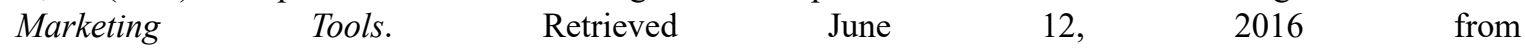
http://www.sbmarketingtools.com/comparison-chart-for-choosing-between-top-social-media-sites-for-mark eting/

Spiliopoulou, A. Y., Mahony, S., Routsis, V., \& Kamposiori, C. (2014). Cultural institutions in thedigital age: British museum's use of Facebook insights. Journal of Audience \& Reception Studies, 11, 286-303.

Vogel, C. (2011, March 16). Museums pursue engagement with social media. The New York Times. Retrieved $\begin{array}{llll}\text { January } 3, & \text { fo16, }\end{array}$ http://www.nytimes.com/2011/03/17/arts/design/museums-pursue-engagement-with-social-media.html?pag ewanted=all

Wadango, B., \& Abdel-Kader, M. (2014). Contingency theory, performance management and organizational effectiveness in the third sector. International Journal of Productivity and Performance Management, 63(6), 680-703. https://doi.org/10.1108/IJPPM-09-2013-0161

Weber, A. S. (2012). Considerations for social network site (SNS) use in education. International Journal of Digital Information and Wireless Communication, 4, 306-321.

Yin, R. K. (1984). Case study research: Design and methods. Newbury Park, CA: Sage.

\section{Copyrights}

Copyright for this article is retained by the author(s), with first publication rights granted to the journal.

This is an open-access article distributed under the terms and conditions of the Creative Commons Attribution license (http://creativecommons.org/licenses/by/4.0/). 